\title{
Expanded Access Versus Emergency Authorization - Use of Investigational Convalescent Plasma for the Treatment of Patients with Severe or Life- Threatening COVID-19
}

\author{
Betancourt-Garcia, M.M. ${ }^{1,2}$, Arauco-Brown, A. ${ }^{1,2}$, Garcia, R. ${ }^{1,2}$, Ramos R.C. ${ }^{1,2}$, and Rao, S. ${ }^{1,2^{*}}$ \\ ${ }^{1}$ DHR Health, Edinburg, Texas, USA \\ ${ }^{2}$ DHR Health Institute for Research \& Development, Edinburg, Texas, USA \\ *Corresponding Author E-mail: s.rao@dhr-rgv.com
}

Received: August 21st, 2020

Accepted for publication: August 24, 2020

Published August 25, 2020

Keywords: COVID-19; Convalescent plasma; Food and Drug Administration; SARS-CoV-2

Some confusion has been created by the recent news that the United States Food and Drug Administration (FDA) has placed on "hold" the decision to grant emergency use authorization (EUA) of investigational convalescent plasma for the treatment of patients with COVID-19 (1). This decision was based on preliminary analysis of the data which suggested that the use of investigational convalescent plasma under the expanded access program (EAP) has not revealed any substantial benefit of this therapy. Furthermore, it was also suggested that more placebo-controlled clinical studies must be conducted to unequivocally establish the benefit (or otherwise) of investigational convalescent plasma therapy. In both the EUA and the EAP programs, the FDA authorizes an investigational medical product (drug, biologic, or medical device) to be used where there are no comparable or satisfactory alternative therapy options available. However, EUA is sought for single patient use, while the EAP (also referred as compassionate use) involves a larger population with the same life-threatening condition outside of clinical trials. The main differences between each program are outlined in Table 1.

There is no effective therapy that is currently available to treat patients with COVID-19 (2). When the option of the use of investigational convalescent plasma was presented as a potential treatment for severe and lifethreatening infection with SARS-CoV-2, DHR Health Institute for Research \& Development took the lead and established the Rio Grande Valley Collaborative $(R G V C)$ for the Early Diagnosis, Prevention and Treatment of COVID-19. Established in March 2020, this collaborative included eleven (11) hospitals in four counties that served a population of over 1.4 million people. All eleven hospitals are registered in the Mayo Clinic EAP and work under a DHR Health Institute for Research \& Development IRB-approved protocol for the identification and selection of potential convalescent plasma donors.

Working in collaboration with Vitalant - our blood bank partner, a comprehensive team of physicians $(n=89)$, scientists, coordinators, data analysts and telephone operators were assembled to serve this distinctive program in the United States. A plasma donation call center was established to screen potential donors and to assist with the process of plasma donation. The RGVC was also involved in the Valley-wide distribution of investigational convalescent plasma to qualified hospitalized patients

While the implementation of the EUA has been placed on hold by the FDA with the possibility of approval in the very near future, it must be clarified that this decision by the FDA does not affect the EAP that is currently active under the Mayo Clinic protocol (3). Todate, in the Mayo Clinic EAP, 2,788 sites have been registered Nation-wide involving 14,204 physicians and 71,185 patients who have received investigational 
Table 1: Comparison between Expanded Access Program and Emergency Use Authorization

\begin{tabular}{|l|l|l|}
\hline & \multicolumn{1}{|c|}{$\begin{array}{c}\text { Expanded Access Program } \\
\text { (Compassionate Use) }\end{array}$} \\
\hline $\begin{array}{l}\text { Patient Population and } \\
\text { Criteria of Use }\end{array}$ & $\begin{array}{l}\text { Patients with serious disease, and no alternative } \\
\text { treatment available. }\end{array}$ & $\begin{array}{l}\text { Patients must have a life-threatening condition } \\
\text { and no alternative treatment. }\end{array}$ \\
\hline $\begin{array}{l}\text { Institutional Review Board } \\
\text { (IRB) and FDA Approval } \\
\text { Requirements }\end{array}$ & $\begin{array}{l}\text { Documents submitted to the IRB and FDA for } \\
\text { approval prior to use }\end{array}$ & $\begin{array}{l}\text { FDA and IRB approval sought after treatment is } \\
\text { given }\end{array}$ \\
\hline Population Size & Intermediate Population Access/Widespread Use & Individual Patient Access \\
\hline Clinical Trial Status & $\begin{array}{l}\text { Investigational Product Clinical Trials are still } \\
\text { ongoing }\end{array}$ & $\begin{array}{l}\text { Before or After Clinical Trials have } \\
\text { started/completed }\end{array}$ \\
\hline
\end{tabular}

convalescent plasma (3). Through participation in the Mayo Clinic EAP, the RGVC has successfully transfused over 1,500 units of investigational convalescent plasma in over 1,400 patients with severe and life-threatening COVID-19.

The safety of investigational convalescent plasma in patients with COVID-19 in the Mayo Clinic EAP has already been established (4). A recent publication entitled: Effect of Convalescent Plasma on Hospitalized Patients with COVID-19: Initial ThreeMonth Experience has also provided some preliminary evidence that the use of investigational convalescent plasma is indeed effective (5). Convalescent plasma signals of efficacy were associated with reduced COVID-19 mortality in 35,000-plus patients. Additionally, the seven-day mortality rate was reduced in patients transfused within three days of COVID-19 diagnosis compared with patients transfused four or more days after COVID-19 diagnosis. Similar trends were observed for 30-day mortality rate. Of interest was the observation that the use of convalescent plasma with higher antibody levels was associated with reduced seven-day and 30-day mortality. The cohort in this analysis included a high proportion of critically ill patients, with $52.3 \%$ in the intensive care unit (ICU) and $27.5 \%$ receiving mechanical ventilation at the time of plasma transfusion.

Future Direction. While we are in the process of undertaking detailed analysis of the data obtained from over 1,400 patients accrued in the EAP in the RGVC, there are some key recommendations developed from preliminary analysis and observations made by the RGVC (see below) which should guide the clinical decision process in the use of investigational convalescent plasma in patients with COVID-19:
- Convalescent plasma should be used as early as possible in the course of COVID-19 disease.

- Attempt should be made to quantify the antiSARS-CoV-2 IgG in investigational convalescent plasma prior to transfusion. Whenever possible, only convalescent plasma with anti-SARS-CoV-2 IgG with a titer of 1:160 should be used (6).

- Initiate randomized placebo-controlled clinical trials to unequivocally establish the efficacy (or otherwise) of transfusion of investigational convalescent plasma in the treatment of COVID-19.

- Clinical studies to transfuse investigational convalescent plasma in an outpatient setting should be expanded:

- For prophylactic treatment of children with underlying medical conditions and high-risk exposure to COVID-19 (7).

- For prophylaxis in high-risk front-line workers (8).

- In symptomatic patients within 3-days of COVID-19 diagnosis.

Conclusion. The use of investigational convalescent plasma under the Mayo Clinic EAP to treat patients with severe or life-threatening COVID-19 is still active and recruiting patients. Interim analysis of the data in the Mayo Clinic EAP suggests that this procedure is safe and effective in treating patients with COVID-19. Given that no proven effective treatments exists for COVID-19, it is recommended that the option for transfusing investigational convalescent plasma under the aegis of the Mayo Clinic EAP must be sustained and further expanded under the EUA. 


\section{References}

1. Gumbrecht J, Howard J, Christensen J. FDA emergency authorization of blood plasma for Covid-19 on hold, according to the New York Times. CNN Health. https://www.cnn.com/2020/08/19/health/blood-plasmaemergency-use-on-hold/index.html. Published 2020.

2. Vijayvargia, P., Garrigos, Z.E., Almeda, N. R.C., Stevens, R.W., and Razonable, R. R. Treatment Considerations for COVID-19: A Critical Review of the Evidence (or Lack Thereof). Mayo Clin Proc. 2020 Jul:95(7): 145-1466. doi: 10:1016/j.nayocp.2020.04.027

3. Mayo Clinic. COVID-19 expanded access program. https://www.uscovidplasma.org/. Published 2020.

4. Joyner, M.J., et.al. Safety Update: COVID-19 Convalescent Plasma in 20,000 Hospitalized Patients. Mayo Clin Proc. 2020 Jul: doi: https://doi.org/10.1016/j.mayocp.2020.06.028

5. Joyner MJ, Bruno KA, et al. Safety Update: COVID-19 Convalescent Plasma in 20,000 Hospitalized Patients. Mayo Clin Proc. 2020;95(x):xx. https://els-jbs-prodcdn.jbs.elsevierhealth.com/pb/assets/raw/Health Advance/journals/jmcp/jmcp_ft95_6_8.pdf.

6. United States Food and Drug Administration. Recommendations for Investigational COVID-19 Convalescent Plasma. Vaccines Blood and Biologics.

https://www.fda.gov/vaccines-blood-biologics/investigationalnew-drug-ind-or-device-exemption-ide-process-

cber/recommendations-investigational-covid-19-convalescentplasma. Published 2020.

7. Deville JG. Covid-19 Convalescent Plasma as Prevention and Treatment for Children With Underlying Medical Conditions.; 2020. https://clinicaltrials.gov/show/NCT04462848\%0A.

8. Ohadian Moghadam S. A Review on Currently Available Potential Therapeutic Options for COVID-19. Int J Gen Med. 2020;13:443-467. doi:10.2147/IJGM.S263666

\section{Disclosures}

Dr. Arauco-Brown is affiliated with the Pulmonary and Sleep Center of the Valley. He is also a faculty member of the UTRGV Internal Medicine Training Program.

Dr. Garcia is affiliated with the South Texas Infectious Disease Consultants.

Dr. Rao serves on the Advisory Board of King Abdulazia University in Jeddah, Saudi Arabia, and as a Senior Advisor to the Vice Chancellor, Dow University of Health Sciences, Karachi, Pakistan. 